\title{
Traffic noise feedback in agent-based Integrated Land-Use/Transport Models
}

\author{
Nico Kuehnel \\ Dominik Ziemke \\ Technical University of Munich \\ Technische Universität Berlin

\section{Rolf Moeckel}

Technical University of Munich

\begin{abstract}
Road traffic is a common source of negative environmental externalities such as noise and air pollution. While existing transport models are capable of accurately representing environmental stressors of road traffic, this is less true for integrated land-use/transport models. So-called landuse-transport-environment models aim to integrate environmental impacts. However, the environmental implications are often analyzed as an output of the model only, even though research suggests that the environment itself can have an impact on land use. The few existing models that actually introduce a feedback between land-use and environment fall back on aggregated zonal values. This paper presents a proof of concept for an integrated, microscopic and agent-based approach for a feedback loop between transportrelated noise emissions and land-use. The results show that the microscopic link between the submodels is operational and fine grained analysis by different types of agents is possible. It is shown that high-income households react differently to noise exposure when compared low-income households. The presented approach opens new possibilities for analyzing and understanding noise abatement policies as well as issues of environmental equity. The methodology can be transferred to include air pollutant emissions in the future.
\end{abstract}

Article History:

Received: July 17, 2020

Accepted: Septem-

ber 7, 2020

Available online: March 15,2021

\section{Introduction}

According to the World Health Organization (WHO), more than 43\% of the urban population in Europe is exposed to road noise levels greater than $55 \mathrm{~dB}$ (A) (WHO 2019), which can impair quality of life and health of affected people. In their paper "Environmental Feedback in Urban Models" from 2008, Spiekermann and Wegener expressed that environmental and ecological aspects have long been ignored in integrated land use/transport models (ILUT) (Spiekermann and Wegener 2008). While some models have been extended by environmental submodules to become land use-transportenvironment (LTE) models, Spiekermann and Wegener highlight that most models only account for effects of land use and transportation on the environment, ignoring the opposite direction. As the

Copyright 2021 Nico Kuehnel, Dominik Ziemke, Rolf Moeckel.

doi: $10.5198 /$ jtlu.2021.1852

ISSN: 1938-7849 | Licensed under the Creative Commons Attribution - NonCommercial License 4.0.

The Journal of Transport and Land Use is the official journal of the World Society for Transport and Land Use (WSTLUR) and is published and sponsored by the University of Minnesota Center for Transportation Studies. 
environment may affect the quality of neighborhoods, noise may also have an impact on land use and - indirectly - travel patterns. Spiekermann and Wegener identified the need for a high spatial resolution as a key requirement for implementing the environmental feedback. Among others, they argue that noise is one of the key environmental factors for which a feedback to land use can be observed in reality. While almost every environmental indicator is affected by land use and transportation, only few of the indicators have a feedback impact on land use. For transport, none of the environmental indicators seem to have a direct impact. Spiekermann and Wegener conclude that, as a minimum, the feedback from the environment to land use by affecting household relocation decisions should be implemented in LTE models. Recent reviews of ILUT models (Acheampong and Silva 2015; Moeckel et al. 2018) confirm that integrated models should better account for environmental (equity) issues in future applications.

This paper presents an implementation of environmental feedback in the microscopic, agent-based FABILUT modeling suite using the example of road traffic noise. The modeling suite allows to link road noise emmissions to dwelling locations of residents microscopically at the coordinate level to account for household relocation impacts. The model is thus capable of representing impacts of land use and transport on the environment and back from environment to land use. This new fully agent-based approach opens new possibilities to analyze issues of environmental equity with the help of models, as population that is emitting and population that is exposed are represented explicitly and can be directly linked throughout the submodels. Complex studies such as location dependent taxes on environmental externalities and their implications on land use, transport and environment will become possible.

\section{Literature Review}

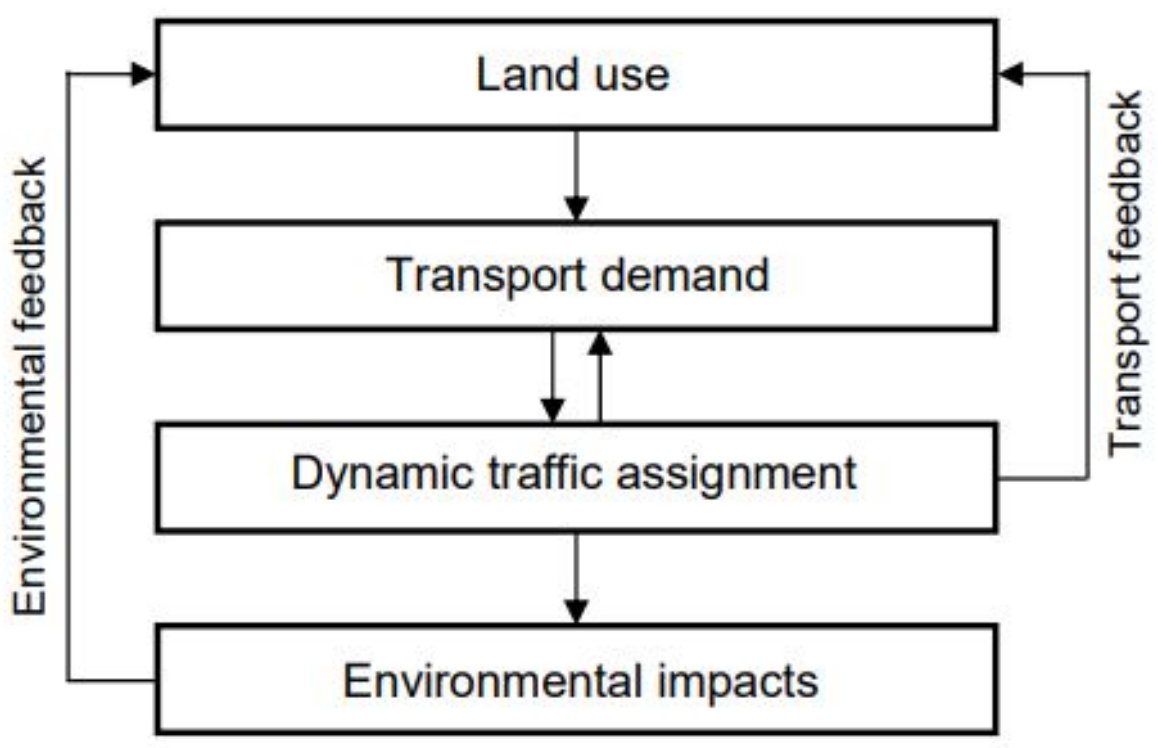

Figure 1: Feedbacks in LTE models (Source: Moeckel et al. 2003)

Previous studies confirmed that noise can be a key factor that affects the willingness to move, relocation choice and satisfaction with housing (Bradley and Jonah 1979). For example, Źróbek et al. (2015) identified that 'quiet neighborhoods' ranked second after 'affordable price' and before other common location factors, such as 'proximity to workplace' or 'Proximity to kindergarten' when asking respondents for neighborhood characteristics of residential properties. Wardman and Bristow (2004) 
showed that reducing noise levels is among the top three of priorities for improvement in residential satisfaction. A similar result has been found by Hanák et al. (2015) when evaluating the perception of the residential environment. Osada et al. (1997) used path analysis to identify that noise significantly increases the willingness to move, which can be explained directly by noise levels and by other indirect consequences including noise annoyance. Lercher and Kofler (1996) show that households who experience noise levels above $55 \mathrm{~dB}(\mathrm{~A})$ are 2.45 times as likely to express a willingness to move. The odds increase to 6.8 for households that express a moderate or strong noise annoyance. When asked for the three main reasons for moving, 'road traffic noise' was the second most common answer which was expressed by $25 \%$ of the people that plan to move in a study carried out by Bendtsen et al. (2000). The impact of noise on residential locations is a complex topic as it not only depends on noise levels alone but also on its perception, sensitivity and even awareness of negative health impacts of noise Han et al. (2015). Shirzadi Babakan and Alimohammadi (2016) presented an agent-based approach of residential relocation choice for the city of Tehran. In their model, they account for noise and air pollution. They were able to show that households with higher income tended to be less exposed to noise than others.

The negative impact of road traffic nuisances on housing is twofold - noise reduces housing satisfaction of residents and, in some cases, can lead to a reduction in property values (Maloir et al. 2009). A typical link between land use and traffic noise thus is the impact of noise on real estate prices which has extensively been reviewed in previous studies (Bateman et al. 2001; Kim et al. 2007; Szczepańska et al. 2014; Theebe 2004). A typical indicator is the noise sensitivity depreciation index (NSDI) which is the percentage change in housing prices caused by an increase of $\mathrm{dB}(\mathrm{A})$ in noise level exposure. Typical values range from $0.08 \%$ to $2.22 \%$ per $\mathrm{dB}(\mathrm{A})$ (Bateman et al. 2001). While the impact of traffic noise on property values has been studied widely, little research is available that deals with impacts of noise on relocation choice.

Not every person is equally sensitive to noise. While biological responses to noise exposure appear to be very similar across the population, the psychological response can differ greatly. This can lead to the phenomenon of residential self-selection, where people who are less sensitive to noise will benefit from more affordable property prices and are more willing to move to more noisy areas (Weinhold 2008). However, a study by Niland et al. did not find evidence for the existence of a residential selfselection phenomenon due to noise (Nijland et al. 2009). If the effect exists it is apparently not easy to detect it.

The DELTA integrated land use/transport model incorporates environmental indicators such as noise and air pollutants based on outputs of the transport model (Simmonds 2010). In this model, the indicators have either been calculated as zonal values per indicator or as a single traffic-density measure as a proxy for environmental impacts. Simmonds argues that color- and odourless gases like air pollutants will most likely not trigger a response in relocation choice. In addition, the paper also recognized that meaningful zonal values might be problematic. The paper concluded that it is reasonable to assume that negative impacts will affect the whole area and not just individually exposed dwellings. In the DELTA model, the environmental impact on relocation is represented by an environmental quality variable which consists of multiple components, including noise and pollutants. The weight of the impact is based on willingness-to-pay values for a reduction in these environmental stressors. The issue of zonal aggregation in the feedback is one of the main issues to be overcome by the approach presented in this study.

Another example of an LTE model is the ILUMASS (Integrated Land-Use Modelling and Transportation System Simulation) project which aimed at microscopically linking transport and land use models. It was also intended to feed back environmental impacts to the land use model (Beckmann 
et al. 2007). The study area Dortmund was divided into 352,000 grid cells of $100 \times 100 \mathrm{~m}$ size to be able to generate meaningful emission values. However, due to the complexity of the project, very long model run times and a file-based data transfer, the ambitious goals were not met (Wagner and Wegener 2007). While the environmental sub-module was working for a small test scenario, it never became operational for the entire integrated model.

The literature review suggests that environmental emissions (and foremost noise) affect household relocation, but there are only few approaches that succeeded to explicitly model this feedback in an integrated land use/transport model, but in an aggregated fashion. In a recent paper, Spiekermann and Wegener (2018) conclude that no full-scale microsimulation of urban land use, transport and environment has become operational and that the environmental feedback has not yet been implemented.

The modeling approach presented in this study, which links land use and transport microscopically, has been described in previous papers (Moeckel and Nagel 2016; Ziemke et al. 2016) which concludes that this integration allows to base small-scale location choices on environmental impacts.

\section{Modeling Suite}

In this study, the integrated land use/ transport modeling suite FABILUT (flexible, agent-based integrated land use/transport, Kuehnel et al.2020; Ziemke et al. 2020) is used to implement the environmental feedback. It consists of the land use model SILO (Simple, Integrated Land-use Orchestrator, Moeckel 2016) and the transport simulation model MATSim (Multi-Agent Transport Simulation, Horni et al. 2016).

SILO models demographic events like birth, marriage and death, household relocations as well as real-estate updates, such as construction, renovation and price updates in year-by-year time-steps. The model incrementally updates an initial synthetic population in which each dwelling, household, person and job is represented individually (Moreno and Moeckel 2018). In particular, each dwelling and job as geo-referenced to a microscopic coordinate which makes it feasible to model accurate individual noise values for each of the dwellings.

MATSim is an activity-based transport modeling framework in which each person is represented as an agent that tries to realize an individual plan. A plan consists of a sequence of activities and intervening trips of a representative day. MATSim is based on a co-evolutionary approach based on the concept of individual utility maximization, in which traffic simulation, scoring of plans and replanning of components of the plan are iteratively repeated until a stochastic user equilibrium is reached. Traffic is simulated using a computationally efficient queue model. As such, MATSim allows to simulate large scenarios with several million of agents while maintaining the integrity of the agents throughout all simulation stages.

Ziemke et al. (2020) described the integration of SILO and MATSim into the FABILUT modeling suite and the specifics of the interplay of the model components in more detail. For this study, the transport demand model MITO (Microscopic Transportation Orchestrator, Moeckel et al. 2020) is plugged into the modeling suite to create individual trips of the whole population for an entire day, which is necessary to obtain meaningful daily noise values. MITO is based on household travel survey data and accounts explicitly for travel time budgets within households and follows an agent- and trip-based approach.

The environmental submodule in the presented approach largely relies on the noise extension of MATSim by Kaddoura et al. (Kaddoura et al. 2017). It is based on the German guideline for noise protection at streets (RLS90) FGSV (1990) which defines how road traffic noise is estimated. The 
estimation takes into account link volumes, vehicle speeds and heavy vehicle shares, among others, to calculate per-link emissions for a given time interval. The resulting emission $E$ of a link $i$ for a given time interval $t$ is calculated as

$$
E_{i, t}=E_{i, t}^{25}\left(p_{i, t}\right)+D_{i}^{v}\left(p_{i, t}\right)
$$

where $E_{i, t}^{25}$ is the emission of link $i$ at time interval $t$ for a set of assumptions (fixed distance of 25 meters, height of 2.25 meters, speed level of $100 \mathrm{~km} / \mathrm{h}$, smooth road surface, gradient less than 5\%), depending on the share of heavy vehicles $p_{i, t} . D_{i}^{v}\left(p_{i, t}\right)$ is a correction for speeds below $100 \mathrm{~km} / \mathrm{h}$ and also depends on the share of heavy vehicles. For equations of $E_{i, t}^{25}$ and $D_{i}^{v}\left(p_{i, t}\right)$ see FGSV (1990). Immissions can then by approximated for defined receiver points $j$ by logarithmic addition of noise values of nearby road links:

$$
L_{\mathrm{eq}, j, t}=10 * \log _{10}\left[\sum_{i} 10^{0.1 * L_{i, j, t}}\right] \quad L_{i, j, t}>0,
$$

where $L_{\mathrm{eq}, j, t}$ is the resulting average hourly immission level at receiver point $k$ in time interval $t . I_{i, j, t}$ is the immission level in $\mathrm{dB}(\mathrm{A})$ resulting from a single given link or road segment and is calculated as

$$
L_{i, j, t}=E_{i, t}+D_{i, j}^{d}+D_{i, j}^{\alpha}-D_{i, j}^{z},
$$

where $E_{i, t}$ is the emission of link $i$ following equation $1, D_{i, j}^{d}$ is a correction term for the distance between receiver point $j$ and link $i, D_{i, j}^{\alpha}$ is an angle correction following Bendtsen (1999) and $D_{i, j}^{z}$ is the correction for shielding which has been implemented in a previous study as an extension to the original MATSim noise extension and allows to take shielding of buildings into account Kuehnel et al. (2019). The correction terms are the computationally most demanding part of the noise estimation. However, they are independent from traffic volumes and only depend on the spatial alignment of receiver points and links. Therefore, in the integrated model, correction terms are only calculated once for every dwelling throughout the simulation years, which greatly reduces runtime for subsequent years, as correction terms are only computed for newly constructed dwellings.

The high temporal and spatial resolution in MATSim allows to obtain noise emissions and immissons over the course of a day for microscopic $\mathrm{x} / \mathrm{y}$ coordinates. A typical indicator for noise exposure at a receiver point $j$ is the aggregated $L_{\mathrm{DEN}, j}$ value ('day-evening-night noise level') which expresses noise level over an entire day. The aggregated term adds up hourly noise immission values $L_{\mathrm{eq}, j, t}$ with extra penalty $\tau$ of $5 \mathrm{~dB}(\mathrm{~A})$ and $10 \mathrm{~dB}(\mathrm{~A})$ given to evening $(6 \mathrm{pm}-10 \mathrm{pm})$ and night (10pm-6am) values, respectively:

$$
\begin{aligned}
& L_{\mathrm{DEN}, j}=10 \cdot \log _{10}\left[\frac{1}{24}\left(\sum_{t=0}^{23} 10^{0.1 \cdot\left(L_{\text {eq }, j, t}+\tau(t)\right)}\right)\right], \text { with } \\
& \tau(t)= \begin{cases}0 \mathrm{~dB}(\mathrm{~A}), & 6 \leq t<18 \\
5 \mathrm{~dB}(\mathrm{~A}), & 18 \leq t \leq 22 \\
10 \mathrm{~dB}(\mathrm{~A}), & \text { else. }\end{cases}
\end{aligned}
$$

In an ideal model, agents would derive lower utility from noisy dwellings, thus leading to a reduced demand. The real estate market would then react to the lower demand of noisy dwellings and reduce their prices. In a previous study, the relationship between the simulated noise immission values and their impact on residential rent prices has been confirmed for this modeling suite using hedonic pricing (Kuehnel and Moeckel 2020). It was shown that dwellings with an $L_{\mathrm{DEN}}$ level between $55 \mathrm{~dB}(\mathrm{~A})$ and $65 \mathrm{~dB}(\mathrm{~A})$ are rented for $5.8 \%$ less. For levels above $65 \mathrm{~dB}(\mathrm{~A})$ price discounts of up to $9.6 \%$ were identified. For the sake of simplification, the feedback integration into the FABILUT modeling suite is twofold: 
Relocation of agents is affected by implementing a noise-sensitive choice model. Agents will be less likely to move to noisy places. Different households (or household types) may have different sensitivities to noise.

Prices of dwellings are adjusted by directly linking price discounts to noise levels as reported in the previous hedonic pricing study of revealed price differences.

\subsection{Relocation Choice}

Due to the lack of available data and existing noise-sensitive relocation choice models for Munich, a model developed by Hunt (2010) is implemented and used in this study. It is based on a stated preference survey in which over 1,200 participants had to choose from dwelling alternatives in Edmonton, Canada. Each respondent was asked to imagine moving to a new home. Multiple hypothetical alternatives were presented, with each of them been described with attributes of different levels of prices, air quality, traffic noise, travel time changes to work, school and shopping, among others. Using the respondent's answers, choice model parameters were estimated. Three versions of the model exist, which were estimated for all households and for two subsamples of high-income and low-income households, respectively. It was shown that high-income households are less sensitive to price but more sensitive to noise and vice versa.

SILO uses a three-step approach for residential relocation. In a first step, every household decides on whether it wants to move in the beginning of each year. The probability for the decision to move is based by a comparative evaluation between the current own housing satisfaction and the average satisfaction in the current region. Once a household decided to move, it will look for a target region in a second step. The region choice is a discrete choice based on average vacancy rates, prices, accessibilities and potential commute travel times of household members. The last step is the selection of a vacant dwelling within the chosen region. Therefore, SILO randomly samples 20 different vacant dwellings and evaluates their utility. The choice follows a multinomial logit model:

$$
p(d)=\frac{e^{\beta * u_{d}}}{\sum_{i} e^{\beta * u_{i}}}
$$

where $u_{d}$ is the utility of dwelling $d$ and $u_{i}$ are utilities of all choice alternatives. Utilities in SILO are usually defined in a utility function. The choice model of Hunt works in a similar way and has a linear form:

$$
U_{i}=\beta_{1} * x_{1}+\beta_{2} * x_{2}+\ldots+\beta_{n} * x_{n}
$$

where $\beta_{n}$ is the utility parameter associated with attribute $x_{n}$.

For this study, SILO's own utility function has been replaced by the models that were estimated in Hunt's study. Therefore, multiple adjustments and simplifications had to be made. The impact of noise was found to be negative in terms of utility but was classified as a categorical variable which had to be translated into noise levels in SILO. The original noise category 'Sometimes Disturbing' was dropped, as the magnitude of the estimate was considered inconsistent among the models. Similarly, dwelling types had to be translated between both models. The classifications for low- and high-income households as well as the utility components were reflected by Canadian Dollars which were converted into Euro equivalents. Low-income households were defined as households with an income below EUR 16,000. High-income households have an income above EUR 68,000. Finally, many variables were not (yet) available in the current SILO model (e.g., air quality, travel time to shopping, car and transit costs). However, the utility components in the original model were based on comparative measures to the current home of respondents (e.g., increase of transit costs by $\$ 1$ compared to current housing) or categorical variables that have a default category which is assigned with a utility of 0 . Thus, in this study, we assume that all alternative dwellings are equally good or bad in the utility components that could not be captured in SILO. For instance, the air quality is assumed to never be bad, such that the 
Table 1: Classifications and relocation variables in the models by Hunt and their representation in SILO

\begin{tabular}{rll}
\hline & Hunt & SILO \\
\hline \multirow{5}{*}{ Dwelling Type } & Single Family & Single Family Detached \\
& Duplex & Single Family Attached \\
& Wownhouse & Multi-Family $(2-4$ families $)$ \\
& Highrise & - \\
\hline \multirow{2}{*}{ Traffic Noise } & None & Multi-Family $(5+$ families $)$ \\
& Occasionally just noticeable & $L_{\text {DEN }}<30 \mathrm{~dB}(\mathrm{~A})$ \\
& Constant faint hum & $L_{\text {DEN }} 30-50 \mathrm{~dB}(\mathrm{~A})$ \\
& Sometimes disturbing & $L_{\text {DEN }} 50-60 \mathrm{~dB}(\mathrm{~A})$ \\
& Frequently disturbing & - dropped - \\
\hline \multirow{2}{*}{ Rent/Tax } & CAD 100 per month increase & $L_{\text {DEN }}<60 \mathrm{~dB}(\mathrm{~A})$ \\
\hline \multirow{2}{*}{ Travel to work } & 10 min auto drive time increase & EUR 68 per month increase \\
& 10 min transit ride increase & 10 min auto drive time increase \\
& & 10 min transit ride increase
\end{tabular}

utility component for all dwellings is 0 . Likewise, variables like ' $1 \$$ transit fare increase to work' which compares fares between current housing and and the potential new dwelling were assumed to yield a difference of zero, i.e., all dwellings would have the same transit fare costs associated to them. Table 1 shows the selected variables that are captured in SILO and their representation.

\subsection{Pricing}

In SILO, the pricing model is run once at the end of each simulation year. Prices of each dwelling type are adjusted according to the current vacancy rate of this housing type in the neighborhood. Prices increase steeply when the vacancy of a dwelling type in a region is low, since it means that a high demand is present. Higher vacancy rates will cause the dwelling prices to drop, but less steep so as landlords are less willing to accept a decrease in rent revenues. The model does account for a certain structural vacancy rate at which the market is considered to be at equilibrium and prices do not change. However, this model reflects the regional price trends of municipalities or districts in Munich. The individual price discount of dwellings because of road traffic noise are implemented in a way that agents will perceive a discount on rent prices when evaluating a dwelling which is exposed to noise. That means that the price discount will only be visible for agents assessing a certain dwelling as defined in the previous section.

It was required to implement both sensitivities for relocation and for price into the model. If only the price was updated, all households would perceive the less expensive dwellings as more attractive even though there is a reason why the dwelling costs less. If only the relocation choice model was adapted, the price discounts found in the hedonic pricing study would not be part of the model and the reduced demand would not lead to differences in the housing market. While one could say that the two effects would 'cancel' each other since the less attractive noisy dwelling is also cheaper, this should still lead to a more distinguished pattern of household distribution. More affluent households are more sensitive to noise and less sensitive to price and will thus afford to move out of noisy places. Less affluent households are much more sensitive to price and are less likely to afford to move away from noisy places, especially in tight housing markets.

Resulting reactions to noise can be explained by looking at figure 2. The utilities of dwellings that only vary in their noise levels are evaluated by the three different household types, compared to a fixed 'current dwelling'. It can be seen that, in general, the higher noise categories are less favorable as they result in less utility. While the high-income households have a high sensitivity to noise and react more and more negatively to higher noise levels, the reaction is less clear in the other two household types. 
Loud dwellings which exceed the price discount thresholds are rented for a lower amount of rent. Less affluent households are much more sensitive to price, which is why the average household group has a less steep decrease in utility. In the case of low-income households, the potentially high price discounts can actually lead to a better utility when compared to more quiet dwellings which do not get price discounts. Since the thresholds for the noise categories in the utility function and for the price discounts differ, the two categories 'Constant' and 'Frequent' show some variation in utilities. Two dwellings with noise values of $64 \mathrm{~dB}(\mathrm{~A})$ and $66 \mathrm{~dB}(\mathrm{~A})$ will both fall into the 'Frequent' noise category while the first will only qualify for the $55-65 \mathrm{~dB}(\mathrm{~A})$ discount and the latter experiences the discount for values above $65 \mathrm{~dB}(\mathrm{~A})$.

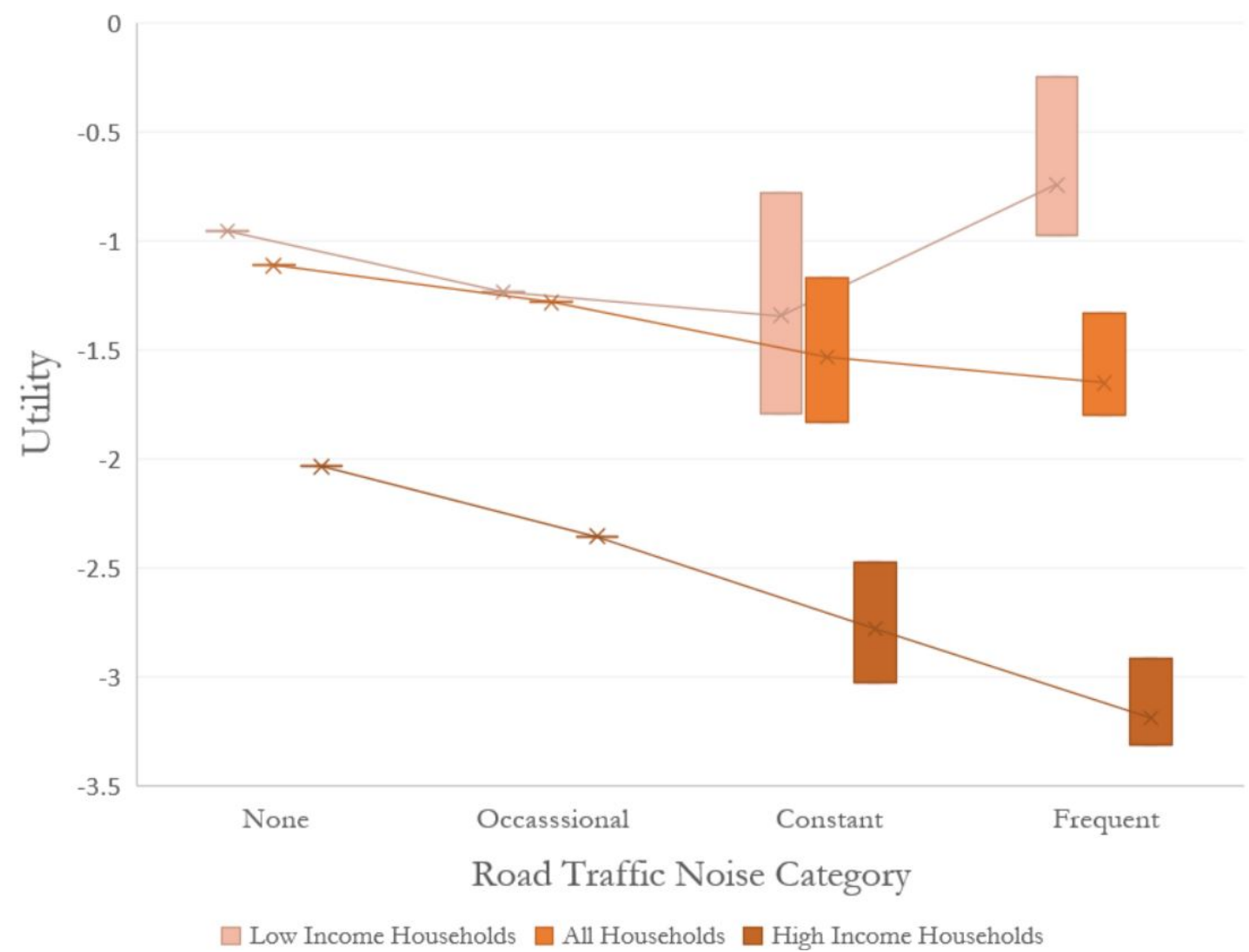

Figure 2: Comparison between noise sensitivities for different household types. The utility is calculated for dwellings with fixed similar attributes, only varying by noise.

Referring to figure 1 , figure 3 shows the actual implemented components of the FABILUT modeling suite including the environmental submodule which is the noise contrib of MATSim. After every transport model execution, noise immission values are updated for all dwellings. In between transport model execution years, traffic state is assumed to be constant. For newly constructed dwellings, the noise submodule will calculate immission values based on latest traffic conditions at the end of the year.

\section{Study Area and Scenario Setup}

The FABILUT modeling suite is applied to a study area of the greater Munich metropolitan area in Germany. In addition to Munich, the four major cities of Augsburg, Ingolstadt, Landshut and Rosenheim are included in the study region. The synthetic population consists of 4.5 million inhabitants in 2.2 million households living in roughly the same amount of dwellings (plus vacant dwellings). It was 


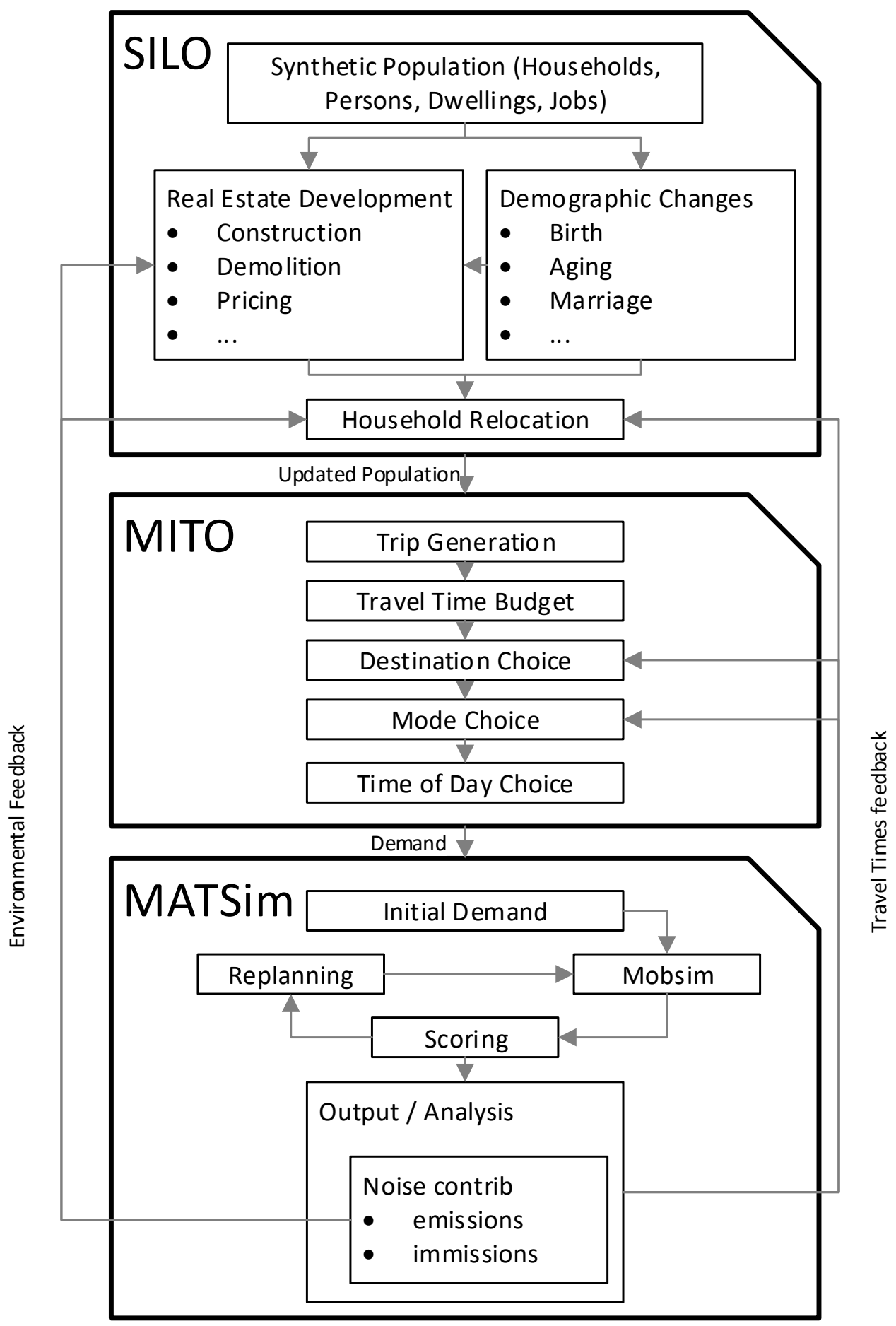

Figure 3: Implementation of the presented modeling suite 
created using an iterative proportional updating procedure (Moreno and Moeckel 2018). The actual dwelling coordinates have been allocated to actual residential building objects as classified by OpenStreetMap (OSM, OpenStreetMap contributors 2019), which is important to improve the realism of experienced noise levels. The polygons of those buildings are additionally used as an input for the shielding effect of buildings in the immission calculation, as described in Kuehnel et al. (2019). For the transport assignment and noise calculations in MATSim, a road network has also been obtained from OSM. The network consists of 142,703 links and covers all medium to major roads in the study area. While the whole synthetic population of SILO is sent to MITO in every transport model year resulting in roughly 8.8 million trips out of which 3.5 million trips are done by car - a subsample of $5 \%$ is actually assigned in MATSim to reduce computation times. The assumptions and validity of this setup in this study area have been confirmed in an earlier study by Llorca and Moeckel (2019).

Two setups were run to verify the implementation. In both setups, the model was run between 2011 and 2030 with transport model executions in the years 2011,2018,2024 and 2030. Relocations were tracked microscopically which allows to trace the movement of households grouped by different socioeconomic traits, especially income. In the first setup, households use the newly implemented relocation strategy based on Hunt, with the exception that all dwellings are perceived as equally (not) noisy, meaning that all dwellings get assigned the same 'None' noise base category in the utility function. In addition, no price discounts are applied This setup will be referred to as the noise-insensitive model. The second setup uses the actual translated noise category as defined in table 1 and applies the presented noise-related price discounts This setup will be referred to as the noise-sensitive. The hypothesis is that, in the noise-insensitive model, no significant discrimination by income should be detectable. To verify this, noise levels are still calculated for each dwelling, even though they are not used in the utility function. In the noise-sensitive model however, high income households should tend to move to less noisy places as they are less sensitive to price and more sensitive to noise as compared to low income households for which the opposite is true. Next to the hypothesis that the spatial distribution of households will be different between the two setups it will be examined whether the exposure to traffic noise generally increases, as population and its density and thus traffic are increasing in the study area.

Therefore, the average incomes of households living in highly and less exposed dwellings will be compared between the setups. In addition, the average $L_{D E N}$ of dwellings of high and low income households will be compared.

\section{Application and Findings}

As stated earlier, the presented approach tries to overcome issues of aggregated zonal values. To verify that the aggregation of local noise immissions to zonal values indeed is problematic, the standard deviation of $L_{D E N}$ levels have been calculated for every zone and the dwellings contained within. As zones and network differ in size and density, standard deviations have been grouped by locations to distinguish between the five core cities 'Munich', 'Augsburg,' 'Rosenheim', Ingolstadt' and 'Landshut' and the remaining zones, here called 'Rural'. Figure 4 shows the distribution of standard deviations for each of the defined locations. Note that this figure shows the distribution of standard deviations of noise immissions for multiple zones and not the distribution of noise levels. It becomes clear that standard errors are quite big in rural zones, which is expected as zones and network are more coarse. With the exception of Rosenheim, the five core cities reveal smaller standard deviations per zone. However, even in Munich were zones are typically quite small $(200 \times 200 \mathrm{~m})$, the mean standard deviation of noise levels is around $4.75 \mathrm{~dB}(\mathrm{~A})$ and the mean range between minimum and maximum noise immission within a zone is $19.5 \mathrm{~dB}(\mathrm{~A})$. For Rosenheim the reported values seem to overestimate the variance within zones. This could be due to some network issues as there were some unrealistically high congested links. All in all the findings support the hypothesis that the aggregation of immission values to 
zonal indicators is problematic and can cloud local differences.

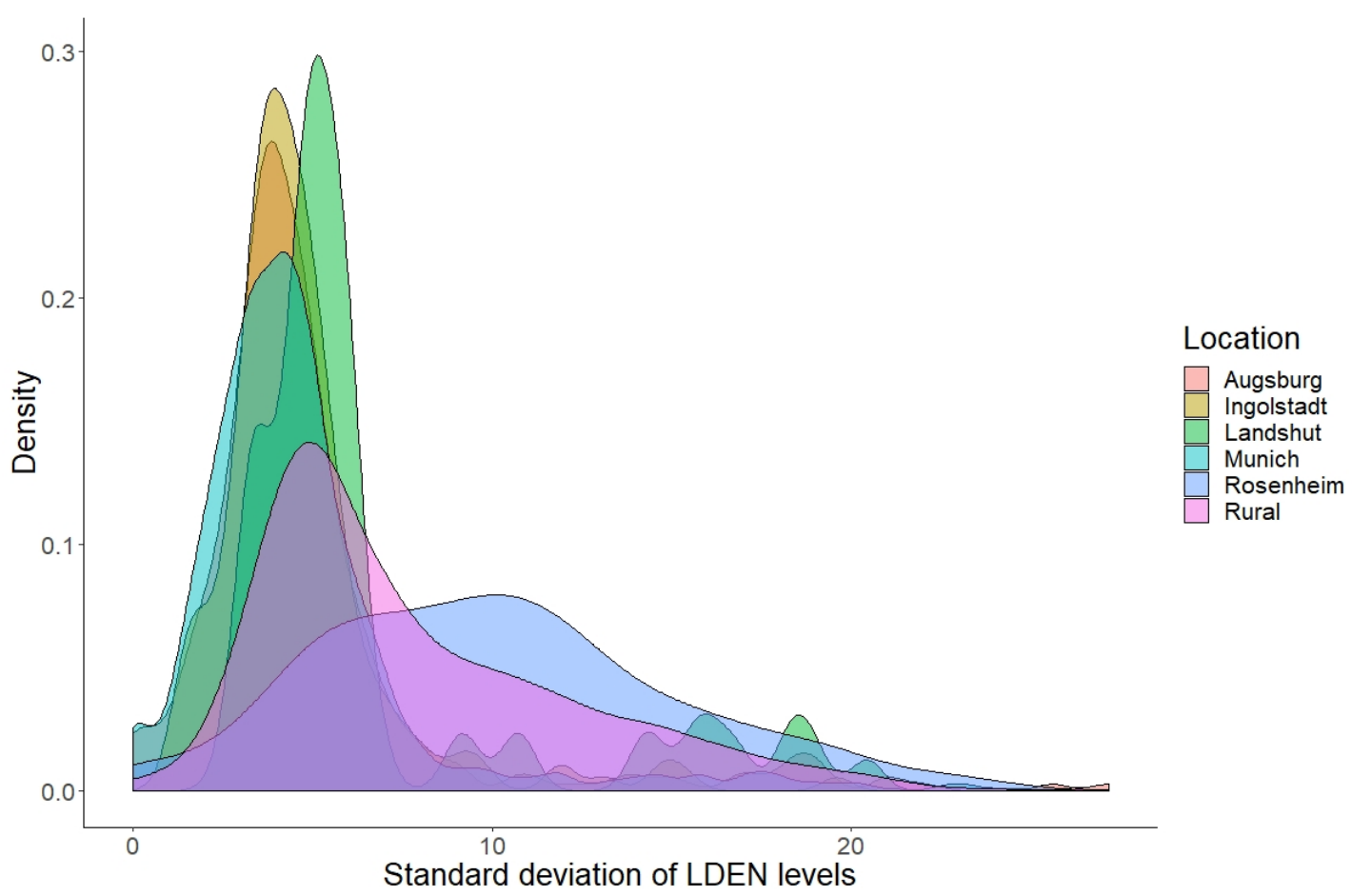

Figure 4: Distribution of standard deviations of immission $L_{\mathrm{DEN}}$ values, grouped by location.

Figure 5 shows simulated $L_{\mathrm{DEN}}$ values for microscopic apartment locations in the base year as well as the increase of the aggregated indicator throughout 2030 using the noise-sensitive setup. Only dwellings that existed throughout the whole time period are shown, which excludes dwellings that were built or demolished after 2011. One can clearly see dwellings close to the major motorways in both parts. All dwellings experienced an increase in noise throughout the years. The settlements near major motorways clearly stick out in terms of absolute noise in 2011 and increase of noise until 2030. In addition, Munich as the center of the study area shows a strongly exposed area with a large number of dwellings. Figure 6 shows a close-up of Munich, including the obtained building polygons from OpenStreetMap that were used for the shielding correction. It can be seen that the mapped dwelling locations match to the buildings. Loud apartments can be seen along larger roads while backyards are typically more quiet. The larger spots where no noise value is shown include parks like the English Garden, Theresienwiese and the Olympic Village, among others. Those are places without residential buildings. The resulting simulated price discounts are depicted in figure 7 for the example of Munich. Again, most discounts are close to major roads while more residential neighborhoods do not experience discounts.

While for the analyses shown in figures 5 and 6 the noise-sensitive model was used, table 2 shows a comparison between the noise-insensitive model and the noise-sensitive model in which prices and relocations are affected by noise. Average noise exposure by income and average income by noise exposure are shown for the whole study area and Munich for the year 2011. Note that these values only include households that actually moved in that simulation year and do not represent values for the whole population. Considering the whole study area, highly-exposed households on average show a significant lower income than households that moved to more quiet dwellings in both models. However, 


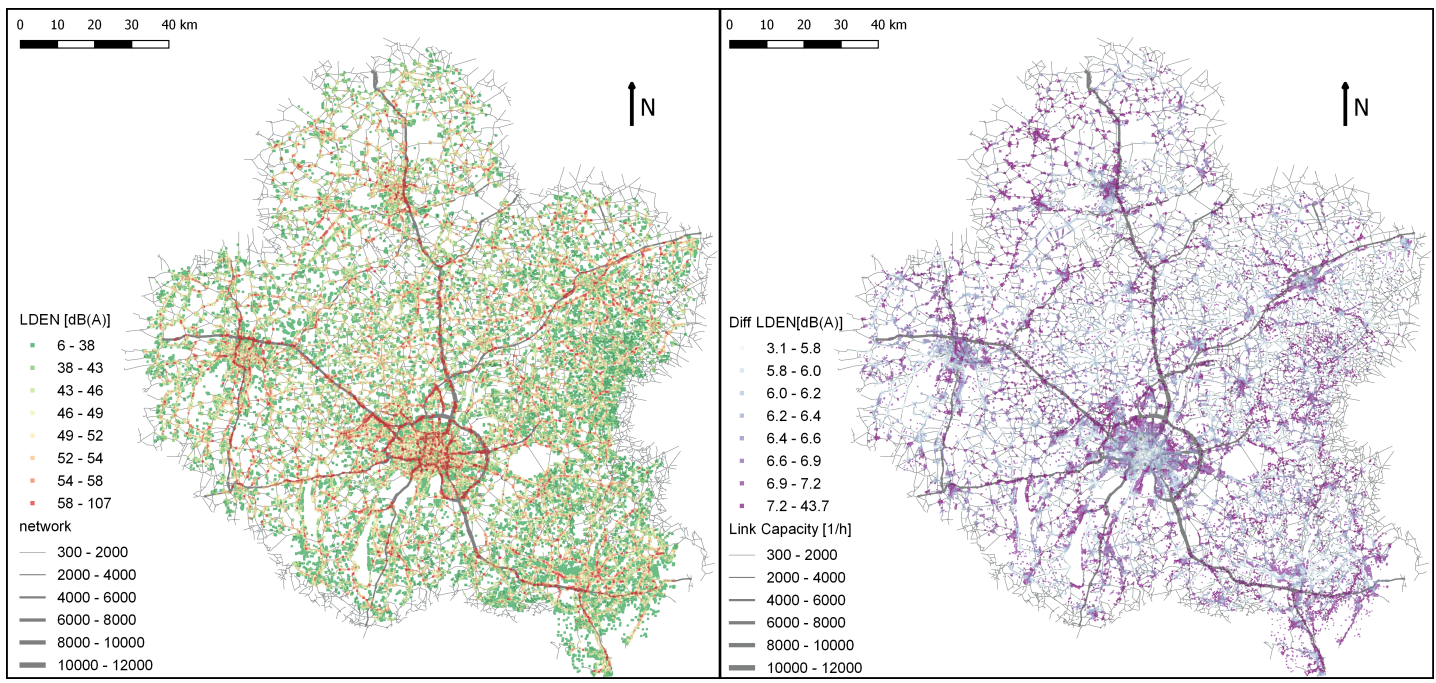

Figure 5: Noise levels in 2011 (left) and increase of noise between 2011 and 2030 (right) as well as link capacities per hour. Noise level ranges based on quantiles.

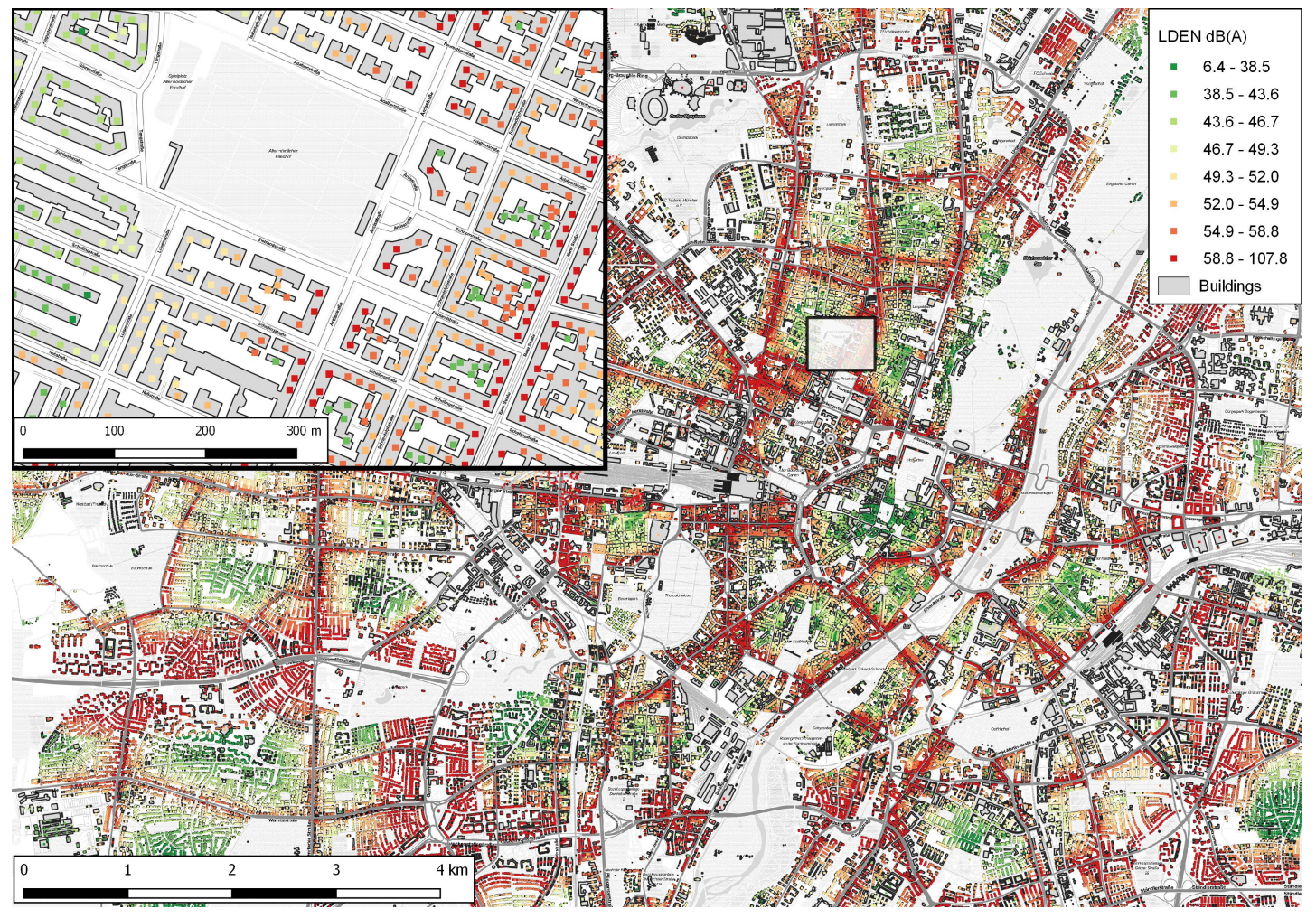

Figure 6: Noise levels in 2011 - close up for Munich including building polygons used for the shielding calculations. 


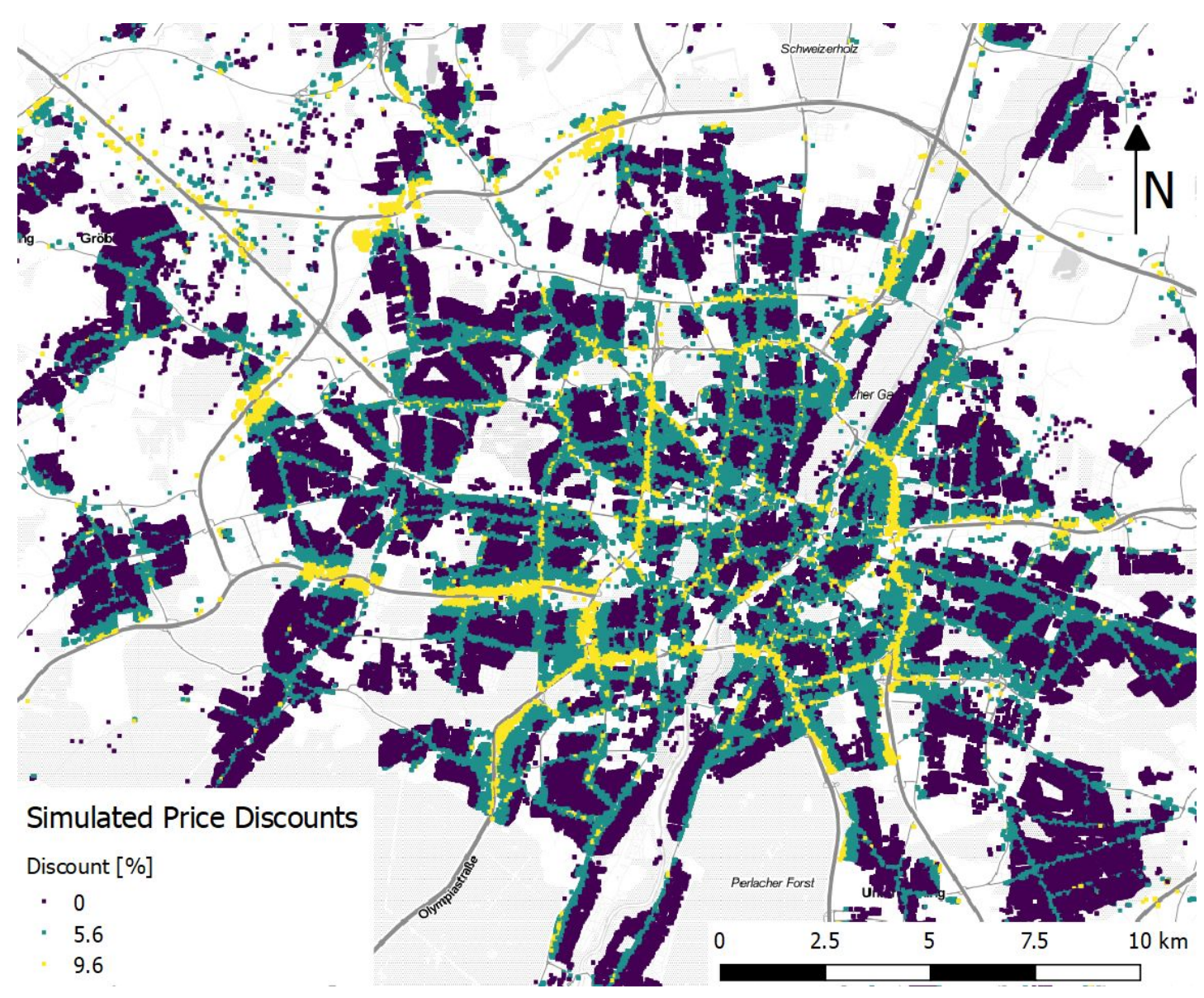

Figure 7: Discounts on rent prices simulated for the year 2011

while the difference in the noise-insensitive model scenario is about 1,500, the difference increases to 3,200 when households and prices react to the noise. Households that move to noisy dwellings thus have an around $11.6 \%$ lower income than households that move to quiet dwellings in the noisesensitive model. A similar direction can be seen when looking at the average noise exposure level. The difference between high and low income households is around $0.9 \mathrm{~dB}(\mathrm{~A})$ in the insensitive model and $2.1 \mathrm{~dB}(\mathrm{~A})$ in the noise-sensitive model. The latter leads to a $4.4 \%$ higher noise level for low income households. For Munich, the difference between average incomes is 2,580 and 531 for the noisesensitive and the noise-insensitive model, respectively. Average noise levels of relocating households are $1.78 \mathrm{~dB}(\mathrm{~A})$ less for high income households in the noise-sensitive model and $0.23 \mathrm{~dB}(\mathrm{~A})$ in the noise insensitive model. It can be observed that average noise levels are higher in Munich which is reasonable as the city is much denser than the rest of the study area.

Even in the noise-insensitive scenario, high income households relocate to less noisy dwellings when looking at the whole study area. This can be explained by the fact that high-income households also put high emphasis on the dwelling type and prefer single family houses in Hunt's model (every dwelling type other than 'single family' yields a worse utility penalty than the loudest noise category for highincome households). As single family homes are more common in more quiet rural sides and suburbs, high-income households will thus still move to more quiet areas even when noise is not used as a parameter for the utility function of the choice model. This effect is much smaller when only looking at relocations to Munich. Here, the differences in income between residents of noisy and quiet dwellings is quite small as multi-family houses are the most common dwelling type and noise is ignored. The noise-sensitive model shows significantly higher reactions to noise in the relocation behavior of high and low income households in the whole study area as well as in Munich alone. 
Table 2: Average income and noise exposure (in $L_{\mathrm{DEN}}$ ) of households that relocated in 2011. Comparison of the noise-sensitive model ('Sensitive') and the insensitive model ('Insensitive').

\begin{tabular}{ll|ll} 
& & Study Area & Munich \\
\hline \multirow{5}{*}{ Sensitive } & $\varnothing$ income, noisy $(>65 \mathrm{~dB}(\mathrm{~A}))$ & EUR 24,570 & EUR 24,177 \\
& $\varnothing$ income, quiet $(<35 \mathrm{~dB}(\mathrm{~A}))$ & EUR 27,805 & EUR 26,758 \\
& $\varnothing$ noise, high inc. $(>\mathrm{EUR} 68,000)$ & $48.42 \mathrm{~dB}(\mathrm{~A})$ & $53.76 \mathrm{~dB}(\mathrm{~A})$ \\
& $\varnothing$ noise, low inc. $(<$ EUR 15,000) & $50.56 \mathrm{~dB}(\mathrm{~A})$ & $55.54 \mathrm{~dB}(\mathrm{~A})$ \\
\hline \multirow{5}{*}{ Insensitive } & $\varnothing$ income, noisy $(>65 \mathrm{~dB}(\mathrm{~A}))$ & EUR 25,700 & EUR 25,207 \\
& $\varnothing$ income, quiet $(<35 \mathrm{~dB}(\mathrm{~A}))$ & EUR 27,294 & EUR25,738 \\
& $\varnothing$ noise, high inc. $(>$ EUR 68,000) & $50.28 \mathrm{~dB}(\mathrm{~A})$ & $54.72 \mathrm{~dB}(\mathrm{~A})$ \\
& $\varnothing$ noise, low inc. $(<$ EUR 15,000) & $49.38 \mathrm{~dB}(\mathrm{~A})$ & $54.95 \mathrm{~dB}(\mathrm{~A})$
\end{tabular}

\section{Discussion and Outlook}

In the presented approach, noise exposures of dwellings/households were successfully traced throughout multiple years in an integrated modeling framework on an individual, microscopic level. Noise exposure levels were calculated for more than two million receiver points that represent dwellings of the land use model. As shown in previous studies, microscopic noise levels vary on a microscopic scale, especially when the impact of shielding is taken into account. This approach can therefore represent noise exposure better than zonal values could. The results suggest that the various household types react differently to road traffic noise, which verifies the functionality of the implementation. Highincome households -on average- relocated to more quiet dwellings than low-income households that tend to take benefit from the price discounts associated with high noise exposure.

The microscopic, agent-based integration may be valuable

- to identify exposure levels of dwellings and households and project them into future years. MATSim's resolution is capable of simulating noise for a typical 24-hour day in fine grained time bins, accurately capturing evening and night time levels.

- to simulate changes in noise exposure due to policies on the land use and the transport model side and the resulting feedback. This could include time-of-day dependent, individual noisesensitive taxes on car commutes, causing agents to relocate closer to their workplace.

- to analyze microscopically who is exposed to and who is emitting road traffic noise to understand and simulate issues of environmental equity. An official report published by the city administration of Munich showed that districts that are exposed to more than $55 \mathrm{db}(\mathrm{A})$ are also more likely to be considered as districts that face sociodemographic challenges such as higher rates of unemployment or a larger share of households with a foreign background (Landeshauptstadt München 2015). Another study by Kistler et al. (2017) found that, in Munich, poor households were twice as likely to be annoyed by noise than more affluent households.

MATSim is also able to model exhaust emissions of road traffic (Kickhöfer and Kern 2015) which means that scenario sensitivity for greenhouse gases and air pollutants can be added in the future. Analyzing the distribution of traffic air pollution is particularly interesting when studying environmental justice. Such emissions factors are also valuable indicators to compare scenarios against each other. However, the impact of exhaust emissions on household relocation and housing prices is expected to be small compared to the impact of noise.

The price adjustment model was calibrated specifically for the Munich study area. It is recognized as a limitation that the relocation choice model developed by Hunt (2010) was simply transferred to this study area without recalibration. Canada and Germany are both developed Western countries. Nonetheless, differences in tastes and behavior are likely to exist. Rent prices, costs of living and average disposable salaries are reported to be quite similar, with an exception of gas prices which are much cheaper in Canada (NationMaster.com 2020). This is accompanied by higher reported average car ownership rates in Canada (Statistics Canada 2020) when compared to Germany (Eurostat 2020), 
which suggests a possible higher dependency on cars. As a proof of concept, however, the presented approach showed plausible and intuitive results.

A shortcoming is that the conversion from categorical variables to a continous immission value is somewhat arbitrary. In addition, Hunt's choice model does not account for the size (in terms of floorspace or number of rooms) of a dwelling, which is one of the most important factors for relocation choice. If household relocation survey data were available for the Munich region, a model could be estimated that better represents local conditions. Another limitation is that MITO does not create (long-distance) freight traffic by default, which can be a substantial source of road traffic noise. A first description of adding freight demand to MITO has been published by Llorca et al. (2019). However, this approach is not yet available in the integrated modeling suite. The MATSim Open Berlin Scenario (Ziemke et al. 2019) uses official counts to retrofit simplistic freight demand, which could be an option to include basic freight at a constant level throughout simulation years. MATSim's noise module is already able to account for heavy duty vehicles which can be added to the setup once available.

While it is shown that traffic noise should be modeled microscopically, the microscopic representation of noise has its drawbacks when looking at future development. As pointed out by Miller (2018), building supply models are usually very simple and unreliable. In SILO, future development decisions are based on a zonal level. The actual coordinates and exact positions are drawn randomly from the zone boundary. As such, future building locations and, thus, receiver points will appear in unrealistic places. For future applications, more effort should be spent on developing reliable building supply and construction models that lead to reasonable spatial positions. This is why, for this paper, only dwellings that existed since the first simulation year were included in the analysis.

It is well known that exposure to noise is not the same as perceived nuisance (Hamersma et al. 2014). As the framework is agent-based, more complex behavior could be represented. For example, Coensel et al. (2007) presented an agent-based approach to explain the perception of environmental stressors. Similarly, modeled noise immissions at the building facade do not necessarily reflect the noise annoyance indoors. A surrogate could be the estimated percentage of people that are highly annoyed at specific immission values, an indicator commonly used in the European Union (Council of the European Union 2002).

Another current limitation is that the network of the study area is rather coarse and does not include minor or small residential roads. Low expected vehicle volumes and noise on those streets can serve as a justification for omitting minor roads, as there is a trade-off between run-time requirements and model resolution. For each of the two scenarios, the presented modeling suite application took about 16 hours to complete on a desktop workstation and requires about 80GB of RAM when building polygons and shielding are included for the whole study area. If no buildings are included, the memory requirement drops to $40 \mathrm{~GB}$. In the current implementation, it was not suitable to simulate a very dense network for the whole study area on a usual desktop working station.

The presented framework fills the gap of microscopically integrating noise as a feedback loop in an existing land-use/transport model. The results confirm the setup and open new possiblities of analyzing environmental stressors such as noise in an integrated context.

\section{Acknowledgments}

Map data copyrighted OpenStreetMap contributors and available from https://www.openstreetmap.org. We would like to thank Wei-Chieh Huang for extracting, processing and preparing the OpenStreetMap data used in the study. We thank Kai Nagel for the discussions and guidance in implementing the communication of noise values between MATSim and SILO. This work was supported by the Deutsche Forschungsgesellschaft (DFG) under project 5051013. It was completed with the support of the Tech- 
nische Universität München - Institute for Advanced Study, funded by the German Excellence Initiative and the European Union Seventh Framework Programme [grant number 291763]. 


\section{References}

Acheampong, R. A. and E. A. Silva. 2015. Land use-transport interaction modeling: A review of the literature and future research directions. Journal of Transport and Land Use, 8(3):11-38. ISSN 19387849. doi: $10.5198 /$ jtlu.2015.806.

Bateman, I., B. Scotland. Development Department., I. Scotland. Scottish Executive., A. University of East Anglia., Economic and Social Research Council (Great Britain), and L. University College. 2001. The effect of road traffic on residential property values: A literature review and hedonic pricing study. Scottish Executive. ISBN 0755900553.

Beckmann, K., U. Brüggemann, J. Gräfe, F. Huber, H. Meiners, P. Mieth, R. Moeckel, H. Mühlhans, H. Schaub, R. Schrader, C. Schürmann, B. Schwarze, K. Spikermann, D. Strauch, M. Spahn, P. Wagner, and M. Wegener. 2007. ILUMASS: Integrated Land-Use Modelling and Transport System Simulation. Technical report, Deutsches Zentrum für Luft- und Raumfahrt.

Bendtsen, H. 1999. The Nordic prediction method for road traffic noise. Science of The Total Environment, 235(1-3):331-338. ISSN 0048-9697. doi: 10.1016/S0048-9697(99)00216-8.

Bendtsen, H., B. Elleberg Larsen, and B. Mikkelsen. 2000. PERCEIVED ANNOYANCE FROM ROAD TRAFFIC NOISE. The 29th International Congress and Exhibition on Noise Control Engineering, (August): $1-5$.

Bradley, J. S. and B. A. Jonah. 1979. The effects of site selected variables on human responses to traffic noise, Part II: Road type by socio-economic status by traffic noise level. Journal of Sound and Vibration, 67(3):395-407. ISSN 10958568. doi: 10.1016/0022-460X(79)90544-3.

Coensel, B. D., T. D. Muer, and D. Botteldooren. 2007. \{A\}n agent based modeling approach to explain the perception of environmental stressors. In Proceedings of the 2007 $\{I\}$ nternational $\{C\}$ onference on $\{$ A\}rtificial $\{$ I\}ntelligence (\{ICAI\} 2007). URL https://biblio.ugent. be/publication/394370/file/587580.

Council of the European Union. 2002. Directive 2002/49/EC of the European Parliament and of the Council of 25 June 2002 relating to the assessment and management of environmental noise. Official Journal L 189, pp. 0012 - 0026.

Eurostat. 2020. Passenger cars in the EU - Statistics Explained. URL https://ec.europa.eu/eurostat/ statistics-explained/index.php/Passenger\{_\}cars\{_\}in\{_\}the\{_\}EU\{\#\}Overview.

FGSV. 1990. Richtlinien für den Lärmschutz an Straßen (RLS). Technical report, Forschungsgesellschaft für Strßen- und Verkehrswesen. URL https://www.fgsv.de/start/.

Hamersma, M., T. Tillema, J. Sussman, and J. Arts. 2014. Residential satisfaction close to highways: The impact of accessibility, nuisances and highway adjustment projects. Transportation Research Part A: Policy and Practice, 59:106-121. ISSN 09658564. doi: 10.1016/j.tra.2013.11.004.

Han, Z. X., Z. H. Lei, C. L.Zhang, W.Xiong, Z. L. Gan, P. Hu, and Q. B. Zhang. 2015. Noise monitoring and adverse health effects in residents in different functional areas of Luzhou, China. Asia-Pacific Journal of Public Health, 27(2S):93S-99S. ISSN 10105395. doi: 10.1177/1010539514560056.

Hanák, T., I. Marović, and P. Aigela. 2015. Perception of residential environment in cities: A comparative study. In Procedia Engineering, volume 117, pp. 495-501. Elsevier Ltd. ISSN 18777058. doi: 10.1016/j.proeng.2015.08.202.

Horni, A., K. Nagel, and K. W. Axhausen, eds. 2016. The Multi-Agent Transport Simulation MATSim. London: Ubiquity Press. ISBN 9781909188754. doi: 10.5334/baw.

Hunt, J. D. 2010. Stated Preference Examination of Factors Influencing Residential Attraction, pp. 2159. Berlin, Heidelberg: Springer Berlin Heidelberg. ISBN 978-3-642-12788-5. doi: 10.1007/9783-642-12788-5_2.

Kaddoura, I., L. Kröger, and K. Nagel. 2017. An activity-based and dynamic approach to calculate road traffic noise damages. Transportation Research Part D: Transport and Environment, 54:335347. ISSN 13619209. doi: 10.1016/j.trd.2017.06.005. 
Kickhöfer, B. and J. Kern. 2015. Pricing local emission exposure of road traffic: An agent-based approach. Transportation Research Part D: Transport and Environment, 37:14-28. ISSN 1361-9209. doi: 10.1016/J.TRD.2015.04.019.

Kim, K. S., S. J. Park, and Y. J. Kweon. 2007. Highway traffic noise effects on land price in an urban area. Transportation Research Part D: Transport and Environment, 12(4):275-280. ISSN 13619209. doi: 10.1016/j.trd.2007.03.002.

Kistler, E., M. Holler, C. Wiegel, O. Schiller, V. Jovcic, and J. Faik. 2017. Expertise III zum Münchner Armutsbericht 2017. Technical report, Internationales Institut für Empirische Sozialökonomie, INIFES $\mathrm{gGmbH}$, Stadtbergen. URL https://www.muenchen.de/rathaus/dam/jcr:fa5b9499-f49b-4ce5-9428-9a0bbf71b4fc/

Expertise3\{_\}von-Inifes-zum-Muenchner-Armutsbericht-2017.pdf.

Kuehnel, N., I. Kaddoura, and R. Moeckel. 2019. Noise Shielding in an Agent-Based Transport Model Using Volunteered Geographic Data. Procedia Computer Science, 151:808-813. ISSN 18770509. doi: $10.1016 /$ j.procs.2019.04.110.

Kuehnel, N. and R. Moeckel. 2020. Impact of simulation-based traffic noise on rent prices. Transportation Research Part D: Transport and Environment, 78:102191. ISSN 13619209. doi: 10.1016/j.trd.2019.11.020.

Kuehnel, N., D. Ziemke, R. Moeckel, and K. Nagel. 2020. The end of travel time matrices: Individual travel times in integrated land use/transport models. Journal of Transport Geography, 88:102862. ISSN 0966-6923. doi: https://doi.org/10.1016/j.jtrangeo.2020.102862.

Landeshauptstadt München. 2015. Münchner Stadtteilstudie. Fortschreibung 2015. Technical report, Referat für Stadtplanung und Bauordnung, Munich. URL https: //www.muenchen.de/rathaus/dam/jcr:1b6d455d-798a-4947-ab57-b8d07d17c7f9/

LHM__S Stadtteilstudie\{_\}Webversion\{_304.pdf.

Lercher, P. and W. W. Kofler. 1996. Behavioral and health responses associated with road traffic noise exposure along alpine through-traffic routes. In Science of the Total Environment, volume 189-190, pp. 85-89. Elsevier B.V. ISSN 00489697. doi: 10.1016/0048-9697(96)05194-7.

Llorca, C. and R. Moeckel. 2019. Effects of scaling down the population for agent-based traffic simulations. Procedia Computer Science, 151:782-787. ISSN 18770509. doi: 10.1016/j.procs.2019.04.106.

Llorca, C., C. Winkler, T. Mocanu, and R. Moeckel. 2019. Long-distance and daily travel demand: integration of various travel markets and modelling approaches. Procedia Computer Science, 151:788793. ISSN 1877-0509. doi: 10.1016/J.PROCS.2019.04.107.

Maloir, C., T. Tillema, and J. Arts. 2009. Residential location preferences, accessibility and road proximity : towards a better or more inclusive infrastructure planning? In Colloquium Vervoersplanologisch Speurwerk, p. 15. Antwerp. URL https://www.cvs-congres.nl/cvspdfdocs/cvs09\{_\}214.pdf.

Miller, E. J. 2018. Integrated urban modeling: Past, present, and future. Journal of Transport and Land Use, 11(1):387-399. ISSN 19387849. doi: 10.5198/jtlu.2018.1273.

Moeckel, R. 2016. Constraints in household relocation: Modeling land-use/transport interactions that respect time and monetary budgets. Journal of Transport and Land Use, 10(2):1-18. ISSN 19387849. doi: $10.5198 /$ jtlu.2015.810.

Moeckel, R., N. Kuehnel, C. Llorca, A. T. Moreno, and H. Rayaprolu. 2020. Agent-Based Simulation to Improve Policy Sensitivity of Trip-Based Models. Journal of Advanced Transportation, 2020:1902162. ISSN 0197-6729. doi: 10.1155/2020/1902162.

Moeckel, R., C. Llorca Garcia, A. T. Moreno Chou, and M. B. Okrah. 2018. Trends in integrated land use/transport modeling: An evaluation of the state of the art. Journal of Transport and Land Use, 11(1). ISSN 1938-7849. doi: 10.5198/jtlu.2018.1205.

Moeckel, R. and K. Nagel. 2016. Maintaining Mobility in Substantial Urban Growth Futures. In Transportation Research Procedia, volume 19, pp. 70-80. ISBN 4989289226. ISSN 23521465. doi: 10.1016/j.trpro.2016.12.069. 
Moeckel, R., K. Spiekermann, C. Schurmann, and M. Wegener. 2003. Microsimulation of land use. International Journal of Urban Sciences, 7(1):14-31. ISSN 21616779. doi: $10.1080 / 12265934.2003 .9693520$.

Moreno, A. and R. Moeckel. 2018. Population Synthesis Handling Three Geographical Resolutions. ISPRS International Journal of Geo-Information, 7(5):174. ISSN 2220-9964. doi: 10.3390/ijgi7050174.

NationMaster.com. 2020. Canada vs Germany Cost of living Stats Compared. URL https://www. nationmaster.com/country-info/compare/Canada/Germany/Cost-of-living.

Nijland, H. A., S. Hartemink, I. Van Kamp, and B. Van Wee. 2009. The influence of sensitivity for road traffic noise on residential location: does It trigger a process of spatial selection? Noise and Vibration Worldwide, 40(3):17-26. ISSN 09574565. doi: 10.1260/095745609788066325.

OpenStreetMap contributors. 2019. Planet dump retrieved from https://planet.osm.org . https:// www.openstreetmap.org.

Osada, Y., T. Yoshida, K. Yoshida, T. Kawaguchi, Y. Hoshiyama, and K. Yamamoto. 1997. Path analysis of the community response to road traffic noise. Journal of Sound and Vibration, 205(4):493498. ISSN 0022460X. doi: 10.1006/jsvi.1997.1016.

Shirzadi Babakan, A. and A. Alimohammadi. 2016. An Agent-Based Simulation of Residential Location Choice of Tenants in Tehran, Iran. Transactions in GIS, 20(1):101-125. ISSN 14679671. doi: $10.1111 /$ tgis. 12144 .

Simmonds, D. 2010. The DELTA residential location model. In Advances in Spatial Science, volume 65, pp. 77-97. Springer International Publishing. doi: 10.1007/978-3-642-12788-5_4.

Spiekermann, K. and M. Wegener. 2008. Environmental feedback in Urban models. International Journal of Sustainable Transportation, 2(1):41-57. ISSN 15568334. doi: $10.1080 / 15568310701517034$.

Spiekermann, K. and M. Wegener. 2018. Multi-level urban models: Integration across space, time and policies. Journal of Transport and Land Use, 11(1):67-81. ISSN 19387849. doi: 10.5198/jtlu.2018.1185.

Statistics Canada. 2020. Vehicle registrations, by type of vehicle. URL https://www150.statcan.gc. $\mathrm{ca} / \mathrm{t} 1 / \mathrm{tbl1} / \mathrm{en} / \mathrm{tv} \cdot$ action? $\mathrm{pid}=2310006701$.

Szczepańska, A., A. Senetra, and M. Wasilewicz. 2014. Traffic Noise as a Factor Influencing Apartment Prices in Large Cities. Real Estate Management and Valuation, 22(3):37-44. ISSN 2300-5289. doi: 10.2478/remav-2014-0025.

Theebe, M. A. J. 2004. Planes, trains, and automobiles: $[t]$ he impact of traffic noise on house prices. The Journal of Real Estate Finance and Economics, 28(2/3):209-234. ISSN 0895-5638. doi: 10.1023/B:REAL.0000011154.92682.4b. arXiv:1112.2903v1.

Wagner, D. P. and D.-I. M. Wegener. 2007. Urban land use, transport and environment models. disP - The Planning Review, 43(170):45-56. doi: 10.1080/02513625.2007.10556988.

Wardman, M. and A. L. Bristow. 2004. Traffic related noise and air quality valuations: Evidence from stated preference residential choice models. Transportation Research Part D: Transport and Environment, 9(1):1-27. ISSN 13619209. doi: 10.1016/S1361-9209(03)00042-7.

Weinhold, D. 2008. How big a problem is noise pollution? A brief happiness analysis by a perturbable economist. MPRA Paper 9885, University Library of Munich, Germany. URL https://ideas.repec. org/p/pra/mprapa/9885.html.

WHO. 2019. European health information gateway. URL https://gateway.euro.who.int/en/ indicators/enhis_52-percentage-of-urban-population-exposed-to-noise-level-lden-55-db/.

Ziemke, D., I. Kaddoura, and K. Nagel. 2019. The MATSim Open Berlin Scenario: A multimodal agent-based transport simulation scenario based on synthetic demand modeling and open data. Procedia Computer Science, 151:870-877. ISSN 1877-0509. doi: 10.1016/J.PROCS.2019.04.120.

Ziemke, D., N. Kuehnel, K. Nagel, and R. Moeckel. 2020. FABILUT: The Flexible Agent-based Integrated Land Use Transport Model. Technical report, Technische Universität Berlin, Berlin. 
URL https://svn.vsp.tu-berlin.de/repos/public-svn/publications/vspwp/2020/20-01.

Ziemke, D., K. Nagel, and R. Moeckel. 2016. Towards an Agent-based, Integrated Land-use Transport Modeling System. In Procedia Computer Science, volume 83, pp. 958-963. ISSN 18770509. doi: 10.1016/j.procs.2016.04.192.

Źróbek, S., M. Trojanek, A.Źróbek-Sokolnik, and R. Trojanek. 2015. The influence of environmental factors on property buyers' choice of residential location in Poland. Journal of International Studies, 8(3):164-174. doi: 10.14254/2071. 